\title{
QUALIDADE FÍSICA DE UM LATOSSOLO VERMELHO SOB PLANTIO DIRETO SUBMETIDO À DESCOMPACTAÇÃO MECÂNICA E BIOLÓGICA(1)
}

\author{
Sérgio Damaso da Silveira J unior ${ }^{(2)}$, Alvaro Pires da Silva ${ }^{(3)}$, Getulio Coutinho \\ Figueiredo $^{(4)}$, Cássio Antonio Tormena ${ }^{(5)}$ \& Neyde Fabíola Balarezo Giarola ${ }^{(6)}$
}

\begin{abstract}
RESUMO
A escarificação e o uso de plantas de cobertura de inverno têm sido adotados para promover a mel horia dos atributos físicos do solo relacionados à aeração. 0 objetivo deste trabal ho foi verificar o efeito das plantas de cobertura de inverno e escarificação nas propriedades físicas de um Latossolo Vermelho distrófico, textura argilosa, após 16 anos em sistema plantio direto. Os tratamentos foram realizados em maio de 2009 e consistiram de: plantio direto (PD), plantio direto com escarificação mecânica a 0,25 m (PD-E) e plantio direto com descompactação biológica por meio da cultura do nabo forrageiro (PD-B). O delineamento experimental foi em blocos ao acaso com quatro repetições, totalizando 12 unidades experimentais. Dezoito meses após a aplicação dos tratamentos, foram coletadas amostras indeformadas de solo em cada unidade experimental, em cinco camadas: 0,0-0,1; 0,1-0,2; 0,2-0,3; 0,3-0,4; e 0,4-0,5 m. Foram avaliados os atributos físicos do solo: porosidade, densidade do solo (Ds), permeabilidade ao ar $\left(K_{\mathrm{a}}\right)$ e índices de continui dade de poros. A $K_{a}$ foi medida por meio de um permeâmetro de carga constante de ar em nove potenciais mátricos $\left(\psi_{m}\right):-0,5 ;-1 ;-2 ;-3 ;-5 ;-7 ;-10 ;-50$; e $-100 \mathrm{kPa}$. Os resultados indicam que os atributos físicos do solo avaliados não foram alterados pelo uso de plantas de cobertura e escarificação. Por outro lado, houve diferenças entre camadas de solo, principalmente entre 0,0-0,1 e 0,1-0,2 m. Na
\end{abstract}

(1) Trabalho de mestrado apresentado pelo primeiro autor no Programa de Pós-graduação em Solos e Nutrição de Plantas ESALQ/USP. Recebido para publicação em 16 de fevereiro de 2012 e aprovado em 03 de outubro de 2012.

(2) Engenheiro Agrônomo. Programa de Pós-graduação em Solos e Nutrição de Plantas da ESALQ/USP. Caixa Postal 9, Av. Pádua Dias 11, CEP 13418-900 Piracicaba (SP). E-mail:sergio.agro@outlook.com

(3) Professor do Departamento de Ciência do Solo, ESALQ/USP. Bolsista do CNPq. E-mail: apisilva@usp.br

(4) Pós-doutor pelo Departamento de Ciência do Solo, ESALQ/USP. E-mail: figueiredo.gc@gmail.com

(5) Professor do Departamento de Agronomia, Universidade Estadual de Maringá - UEM. Av. Colombo, 5790. CEP 87020-900 Maringá (PR). Bolsista do CNPq. E-mail: catormena@uem.br

(6) Professor do Departamento de Ciência do Solo e Engenharia Agrícola, Universidade Estadual de Ponta Grossa - UEPG. Av. Gal. Carlos Cavalcanti, 4748. CEP 84030-900 Ponta Grossa (PR). E-mail: neydef@uepg.br 


\begin{abstract}
camada de 0,1-0,2 m, a Ds foi maior e a porosidade total e $K_{a}\left(\psi_{m}=-5 \mathrm{kPa}\right)$ foram menores do quena camada de 0,0-0,1 m. No PD-E, verificou-se quea macroporosidade foi maior na camada de 0,0-0,1 m em comparação com os outros tratamentos. Os resultados sugerem que o solo estudado submetido aos tratamentos de descompactação, após 18 meses, retornou a valores semelhantes aos da testemunha.
\end{abstract}

\begin{abstract}
Termos de indexação: aeração do solo, permeabilidade ao ar, continuidade de poros, qualidade do solo.
\end{abstract}

\author{
SUMMARY: PHYSICAL QUALITY OF UNTILLED OXISOL SUBJ ECTED TO \\ MECHANICAL AND BIOLOGICAL DECOMPACTION
}

\begin{abstract}
Chiseling and winter cover crops haveben adopted to improvethesoil physical properties related to aeration. This study ai med to eval uatetheeffects of winter cover crops and chiseling on physical properties of a Typic Hapludox, dlayey texture, after 16 years under no-tillage. The treatments were applied in May 2009, as follows: no-tillage (PD), no-tillage mechanically chisel ed to a depth of $0.25 \mathrm{~m}$ (PD-E), and biologically aerated soil with no-tillageradish (PDB). Theexperiment was arranged in a randomized bl ock design, with four repl icates, totaling 12 experimental units. Eighteen months after treatment application, undisturbed soil samples werecollected from fivelayers of each experimental unit: $0.0-0.1 ; 0.1-0.2 ; 0.2-0.3 ; 0.3-0.4$; and 0.4-0.5 m. Thefollowing soil physical properties wereassessed: porosity, bulk density (Bd), $\mathrm{K}_{\mathrm{a}}$ and porecontinuity indices. $K_{a}$ was measured using a constant head air permeameter at nine soil matric potential s ( $\psi_{\mathrm{m}}:-0.5,-1,-2,-3,-5,-7,-10,-50$, and $\left.-100 \mathrm{kPa}\right)$. Theresults indicated that the soil physical properties measured wereunal tered by cover plants and chiseling. In contrast, therewere differences between soil layers, especial ly between 0.0-0.1 and 0.1-0.2 m. In thelayer 0.1-0.2 $\mathrm{m}$, Bd was higher, whereas total porosity and $\mathrm{K}_{\mathrm{a}}\left(\psi_{\mathrm{m}}=-5 \mathrm{kPa}\right)$ werelower than in 0.0-0.1 m. In thetreatment PD-E, macroporosity was higher in the 0-0.1 m layer than in theother treatments. Theresults suggested that thestudied soil returned to values similar to thecontrol 18 months after the decompression treatments.
\end{abstract}

Indexterms: soil aeration, air permeability, porecontinuity, soil quality.

\section{INTRODUÇÃO}

O manejo do solo influi nos atributos físicos do solo, alterando a dinâmica do ar e da água. A ausência de revolvimento dosolonosistema deplantio direto(PD), associada à modernização da agricultura nas últimas décadas, visando à otimização de práticas agrícolas, tem levadoao uso intensivo de máquinas agrícolas de grande portee, consequentemente, mai or intensidade douso das terras (Chamen et al., 2003), de forma que, eventualmente, as operações são executadas em condições de umi dade inadequadas. Nessesistema, é comum a ocorrência de compactação da superfície do solo, oque, dependendo do seu grau, poderá prejudicar as trocas gasosas entre o solo e a atmosfera e, consequentemente, o desenvolvimento das plantas. A renovação do ar do solo e o aumento da concentração de oxigênio são necessários para que o processo de respiração radicular e o metabolismo microbiano aeróbico sejam mantidos em níveis adequados (Scanlon et al., 2002).

Para que o processo de aeração ocorra de forma eficiente, énecessário queexistam poros ocupados por ar, conectados entresi ecom a superfície do solo (Hillel, 1980; Scanl on et al ., 2002). Dessa forma, a aeração do sol o mostra-se dependente da quantidade, tamanho e continuidade dos poros e do conteúdo vol umétrico de água, ou seja, dependente do manejo do solo. Quando este é praticado de forma inadequada, promove a compactação, que ocasiona alterações físi cas no solo, como a redução da continuidade de poros, devido à obstrução e fragmentação destes, comprometendo a funcionalidade do sistema poroso do solo (Landefeld et al., 2004). Um dos princi pais efeitos da compactação é a redução do volume de macroporos (Stone et al., 2002), queconsequentementerestringeo crescimento das plantas, a qual ocorre quando a taxa de difusão de gases nosol oédrasticamentereduzida, porosidadede aeração $\left(\varepsilon_{\mathrm{a}}\right)<0,10 \mathrm{~m}^{3} \mathrm{~m}^{-3}$ (Grable \& Siemer, 1968; Drewry et al., 2008). Vários autores evidenciaram a importância da aeração como fator limitante ao desenvolvimento do sistema radicular das plantas, crescimento e produção das culturas em solos compactados (Letey et al., 1962, 1985; Gerik et al., 1987; Carter et al., 1994).

Diante disso, verifica-se a importância do desenvolvimento e aperfeiçoamento de práticas que visem combater a degradação do solo e, que ao mesmo tempo, busquem a manutenção dos benefícios gerados pela adoção do PD. A escarificação pode ser descrita 
como a ação de uma ferramenta estreita que rompe camadas adensadas e compactadas, com o objetivo de diminuir sua resistência à penetração de raízes e aumentar a aeração ea drenagem interna do solo, de modo a diminuir o escoamento superficial e o tempo de encharcamento (Taylor \& Beltrame, 1980). Além da escarificação mecânica, a descompactação bi ológica inclui o cultivo de plantas que tenham sistema radicular pivotante, capaz de crescer em camadas de sol o compactado (Abreu et al ., 2004; Magal hães et al ., 2009), como o nabo forragei ro (Raphanus sativus), de formar bioporos estáveis emel horar os atributos físicos do solo (Cubilla et al., 2002). Contudo, dependendo do manejo real izado após a escarificação, comoa escol ha das culturas no esquema de rotação e o tráfego, seus efeitos sobre as propriedades físicas do sol o podem ter duração de seis meses a três anos (Franchini \& Debiasi, 2009).

Os impactos na qualidade física do solo, em consequência do seu manejo, podem ser quantificados utilizando-se diferentes atri butos físicos relacionados com a estabilidadeestrutural do solo, como porosidade total, tamanho e continuidade de poros (Beutler et al., 2001). Por sua vez, a permeabilidade do solo ao ar $\left(K_{a}\right)$ representa a resistência imposta pelo solo à passagem do ar e é influenciada pela quantidade, forma, tamanho e continuidade do sistema de poros (Roseberg \& McCoy, 1990). Portanto, a Ka pode ser usada na aval iação das alterações na estrutura do solo causadas pelo seu manejo. $A K_{a}$ e a $\varepsilon_{a}$ têm sido relacionadas na tentativa de avaliar possíveis diferenças na geometria e continuidade dos poros resultantes das práticas de manejo adotadas (Blackwell et al., 1990). Ball (1981a,b) e Shtykov \& Daishev (1986) encontraram correlação linear positiva, sendo satisfatória nas análises de regressão dos dados de $K_{a}$ e de $\varepsilon_{a}$. Dessa forma, os índices de continuidade de poros podem ser indicadores da movimentaçãotridimensional da água e doar no solo, pois estimam a quantidade de poros que são efetivamente utilizados para esses fluxos.

No Brasil há carência de informação sobre $K_{a}$, particularmente por razões metodológicas, tanto associadas aos métodos de medida quanto à disponi bilidade de equi pamentos (Silva et al ., 2009). Recentemente, oavanço da tecnol ogia dos componentes utilizados na construção de permeâmetros permitiu que a $K_{a}$ fosse mais amplamente difundida como ferramenta para aval iação da qualidadefísica dosolo (Figueiredo, 2010).

Há mais de 16 anos a área estudada écultivada no sistema plantio direto. No entanto, o uso do sol o sob esse sistema muitas vezes está associado ao intenso tráfego de máquinas, as quais contribuem para o aumento da compactação (Collares et al., 2006). Assim, este trabal ho teve como objetivo verificar os efeitos de práticas de descompactação mecânica e biológica, aos 18 meses após sua implantação, na qualidadefísica de um Latossol o Vermel ho distrófico textura argil osa sob sistema plantio direto.

\section{MATERIAL E MÉTODOS}

O trabalho foi conduzido na Fazenda Escola da Universidade Estadual de Ponta Grossa, Estado do Paraná, local izada a $25^{\circ} 05^{\prime} 52^{\prime \prime}$ de latitude sul e $50^{\circ}$ 02' 43" delongitudeoeste, com altitude média de 1.080 $\mathrm{m}$. A regiãoapresenta clima mesotérmico, subtropical úmido do tipo $\mathrm{Cfb}$, com precipitação pluvial média anual de $1.545 \mathrm{~mm}$ e temperatura média anual de $18,7^{\circ} \mathrm{C}$ (IAPAR, 2000). Segundo Bhering et al. (2008), osolo da área em estudo foi classificado como Latossolo Vermelho distrófico, pertencente à classe textural argilosa (Quadro 1). A textura foi determinada pelo método do densímetro (Gee \& Bauder, 1986), e a densidade de partículas obtida com a utilização do equipamento ACCUPYC 1330, da Micromeritics Instrument Corporation ${ }^{\circledR}$.

A área do estudo foi conduzida por mais de 16 anos em sistema de plantio di reto, com a seguinte rotação de culturas: milho (Zea mays L.) e soja (Glycinemax L.), no período primavera/verão; e trigo (Triticum aestivum L.) e consórcio aveia-preta (Avena strigosa Schreb) +ervilhaca (Vicia sativa L.), no outono/inverno.

$\mathrm{Na}$ área sob plantio direto, a semeadura foi real izada com disco dupl o a 0,03 m de profundidade para as culturas de inverno e com haste sulcadora a 0,04 m deprofundidade (para deposição da semente) e a 0,10 m (para deposi ção do adubo) para as culturas de verão. Os tratamentos aplicados foram: plantio direto com escarificação mecânica (PD-E), plantio direto com descompactação biológica (PD-B) e testemunha (PD). O delineamento experimental foi o de blocos ao acaso com quatro repetições. As dimensões das parcel as foram de $9 \times 50 \mathrm{~m}$, total izando $450 \mathrm{~m}^{2}$. A escarificação foi realizada em mai o de 2009, utilizando um escarificador J umbo Matic acoplado ao sistema de acionamento hidráulico do trator, ajustado à profundidademédia de $0,25 \mathrm{~m}$, dois dias antes da semeadura da cultura de inverno. No momento da escarificação a umidade média das parcelas era de $29,49 \%$, correspondendo a uma umidade abaixo da capacidade de campo. O escarificador dispõe de cinco hastes (três na barra dianteira e duas na traseira) de formato parabólicoe pontei ra em cinzel, com espaçamento entre hastes de $200 \mathrm{~mm}$ eângulo deataque de $22^{\circ}$. O nabo forrageiro

\section{Quadro 1. Distribuiç̧ão do tamanho de partículas e densidade de partícula (Dp) de um Latossolo Vermel ho distrófico, nas camadas avaliadas}

\begin{tabular}{ccccc}
\hline Camada & Argila & Silte & Areia & Dp \\
\cline { 2 - 4 } $\mathrm{m}$ & \multicolumn{3}{c}{$\mathrm{g} \mathrm{kg}^{-1}$} & $\mathrm{~g} \mathrm{~cm}^{-3}$ \\
$0,0-0,1$ & 506,2 & 52,4 & 441,4 & 2,54 \\
$0,1-0,2$ & 518,4 & 53,3 & 428,3 & 2,58 \\
$0,2-0,3$ & 512,3 & 54,3 & 433,4 & 2,59 \\
$0,3-0,4$ & 520,5 & 54,4 & 425,1 & 2,60 \\
$0,4-0,5$ & 526,2 & 58,3 & 415,5 & 2,60 \\
\hline
\end{tabular}


(Raphanus sativus) foi semeado no outono/invernoem substituiçãoà aveia +ervilhaca, com intuito deverificar o efeito das raízes na descompactação do solo. Foi utilizada uma semeadora/adubadora ajustada para uma densidade deaproximadamente 22 sementes por metro linear e espaçamento de 0,17 $\mathrm{m}$ para a semeadura do nabo forrageiro. 0 trator $4 \times 2$ comTDA, utilizado para preparo do sol o e semeadura, possuía motor com 75,7 kW de potência nominal.

A amostragem do solo foi realizada em outubro de 2010, 18 meses após a descompactação (mecânica e biológica) e no estádio final da cultura do trigo. A aplicação dos tratamentos não al terou omanejo da área experimental, e o tráfego de máquinas continuou ocorrendo em virtude das operações de semeadura, adubação, pulverização e colheita referentes a cada cultura da rotação. Foramselecionados, al eatoriamente, na entrelinha da cultura, 12 pontos deamostragem para cada tratamento. Em cada ponto deamostragem, foram retiradas cinco amostras, nas camadas de $0,0-0,1 ; 0,1$ 0,$2 ; 0,2-0,3 ; 0,3-0,4 ; \mathrm{e} 0,4-0,5 \mathrm{~m}$. Aotodo, foram coletadas 180 amostras indeformadas, em anéis volumétricos de aço inox (0,05 m de diâmetro ealtura), utilizando um disposi tivo el etromecânico que el imina a aplicação de percussão durantea amostragem do sol o (Figueiredo, 2010). A pós a coleta, as amostras foram acondicionadas em filmes de PVC emantidas em temperatura de $5^{\circ} \mathrm{C}$ atéserem processadas.

Após a saturação por capilaridade em água, as amostras foram submetidas, em mesa de tensão e extratores de Richards, aos seguintes potenciais mátricos: -0,5; -1,0; -2,0; -3,0; -5,0; -7,0; -10,0; -50,0 e $-100,0 \mathrm{kPa}$. A pós o equilíbrio hidráulico, as amostras de solo foram pesadas e, imediatamente, foi estabelecido um fluxo de ar, para quantificar a $K_{a}$, utilizando o permeâmetro proposto por Figueiredo (2010). A partir da Lei deDarcy, a densidade defluxo dear (q) [L/T] pode ser descrita pela equação (1):

$$
\mathrm{q}=\frac{\mathrm{K}_{\mathrm{a}}}{\eta}\left(\frac{\mathrm{dP}}{\mathrm{dZ}}+\rho \mathrm{g}\right)
$$

em que $K_{a}\left[L^{2}\right]$ éa permeabilidadeaoar; $P$, a pressão de $\operatorname{ar}\left[\mathrm{M} / \mathrm{LT}^{2}\right] ; \mathrm{z}$, a distância [L] na direção do movimento dear nosistema poroso; $\eta$, a viscosidade do $\operatorname{ar}$ [M/LT]; $\rho$, a densidade do ar [M/L $\left.{ }^{3}\right] ;$ e g, a aceleração da gravidade $\left[\mathrm{L} / \mathrm{T}^{2}\right]$.

A densi dade de fluxo correspondeà vazão dear (Q) $\left[\mathrm{L}^{3} / \mathrm{T}\right]$ por área perpendicular ao movimento do fluido $\left(A_{s}\right)\left[L^{2}\right]$; considerando como desprezível a influência da densidade do ar (Springer et al., 1998), a equação2 foi utilizada para as estimativas da $\mathrm{K}_{\mathrm{a}}$ :

$$
\mathrm{K}_{\mathrm{a}}=\frac{\mathrm{Q} \eta}{\mathrm{A}_{\mathrm{s}}}\left(\frac{\mathrm{dz}}{\mathrm{dP}}\right)
$$

As amostras foram colocadas em estufa a $105^{\circ} \mathrm{C}$ durante período de $24 \mathrm{~h}$, para obtenção de sua massa seca, utilizada no cál cul o da densidade do sol o(Blake \& Hartge, 1986).
A microporosidadefoi obtida a partir do volume de água retida nas amostras indeformadas de solo submetidas à tensão de- $5 \mathrm{kPa}$. A macroporosi dadefoi cal culada pela diferença entre a porosidade total ea microporosidade.

A porosidadetotal ea porosidade de aeraçãoforam obtidas pelas equações 3 e 4, respectivamente:

$$
\begin{gathered}
\mathrm{PT}=1-\frac{\mathrm{Ds}}{\mathrm{Dp}} \\
\varepsilon_{\mathrm{a}}=\mathrm{PT}-\theta
\end{gathered}
$$

em que PT éa porosidade total do solo [ $\left.\mathrm{L}^{3} / \mathrm{L}^{3}\right]$; $D p$, a densidade de partícula do sol o; e $\varepsilon_{a}$, a porosidade de aeração do solo $\left[\mathrm{L}^{3} / \mathrm{L}^{3}\right.$ ], estimada considerando a densidade da água igual a $1,0 \mathrm{Mg} \mathrm{m}^{-3}$. $\theta$ é o teor de água $\left[\mathrm{L}^{3} / \mathrm{L}^{3}\right]$ em cada um dos potencias mátricos aplicados às amostras

A estimativa dos índices de continuidade de poros do solo foi avaliada pela relação entreas propriedades físicas $K_{a}$ e $\varepsilon_{a}$, sendo utilizada a equação de K ozenyCarman, conformeBall et al. (1988):

$$
\mathrm{K}_{\mathrm{a}}=\mathrm{M}\left(\varepsilon_{\mathrm{a}}\right)^{\mathrm{N}}
$$

sendo $\mathrm{M}$ e $\mathrm{N}$ os coeficientes deajuste do model o.

Os val ores do parâmetro N, utilizado comoíndice de continuidade de poros (Ball et al., 1988; Roseberg \& McCoy, 1990), foram estimados mediante a linearização da equação deK ozeny-Carman:

$$
\log \left(K_{a}\right)=\log (M)+N \log \left(\varepsilon_{a}\right)
$$

A interseção da reta, obtida pela equação 6 , como eixolog $\varepsilon_{a}\left(F i g u r a 1, \log K_{a}=0\right)$ expressa a quantidade de poros de aeração bl oqueados no solo $\left(\varepsilon_{b}\right)$, os quais

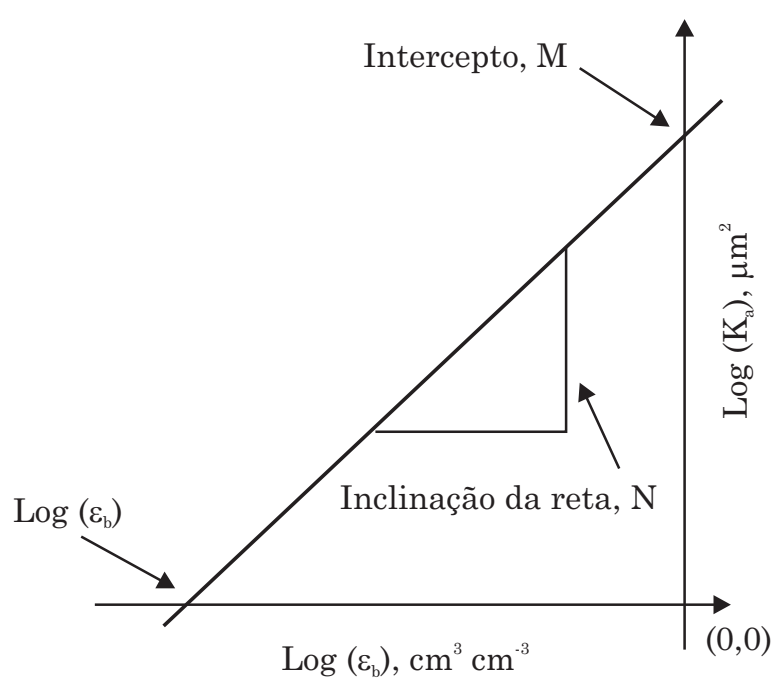

Figura 1. Princi pais características da relação loglog entre a permeabilidade ao ar $\left(K_{a}\right)$ e a porosi dade de aeração $\left(\varepsilon_{\mathrm{a}}\right)$; inclinação da reta, $\mathrm{N}$; intercepto com o eixo $\log \left(\mathrm{K}_{\mathrm{a}}\right), \mathrm{M}$; e limite do conteúdo de ar, $\varepsilon_{\mathrm{b}}$. 
não contribuem para o transporte convectivo do ar (Ball et al., 1988; Schjønning et al., 2002). Dessemodo, $\varepsilon_{\mathrm{b}}$ éo valor de $\varepsilon_{\mathrm{a}}$ abaixo do qual ofluxo de ar através dosolo cessa, devidoà descontinuidade da rededeporos deaeração, e podeser obtido pela equação 7 (\% v/v):

$$
\varepsilon_{\mathrm{b}}=10^{-\log (\mathrm{M}) / \mathrm{N}} \times 100
$$

O índice de continuidade de poros $\mathrm{K}_{1}$, proposto por Groenevelt et al. (1984), foi calculado com base na relação entre $K_{a}$ e $\varepsilon_{a}$ :

$$
\mathrm{K}_{1}=\frac{\mathrm{K}_{\mathrm{a}}}{\varepsilon_{\mathrm{a}}}
$$

O interval o de confiança da média $95 \%(p<0,05)$ foi adotado como critério estatístico para a comparação do efeito dos tratamentos nas médias da Ds, $K_{a}$ e dos índices de continuidade de poros. Diferenças significativas entreas médias ocorreram quando não houve sobreposi ção dos limites superior einferior do interval o de confiança (Payton et al., 2000).

\section{RESULTADOS E DISCUSSÃO}

No quadro 2 são apresentados os resultados da análiseestatística descritiva para a densidade do solo
(Ds), com pequenas diferenças numéricas (máximo $0,06 \mathrm{Mg} \mathrm{m}^{-3}$ ). Os maiores valores de Ds foram observados na profundidade de $0,1-0,2 \mathrm{~m}$, em todos os tratamentos. Os val ores de Ds medidos enquadramse dentro da faixa comumente observada em solos agrícolas de textura argilosa (Brady \& Weil, 2007), especialmente na região estudada (Cavalieri et al., 2009, Figueiredo et. al 2009).

Nos três sistemas de manejo estudados, a Ds apresentou incremento abrupto entre as camadas de 0,0-0,1 e 0,1-0,2 m, e essa diferença permaneceu atéa camada de 0,3-0,4 m (Figura 2). I sso foi menos intenso no plantio direto(PD), que apresentou valor médio de Ds ligei ramente superior ao dos demais tratamentos na camada mais superficial, embora a diferença não fossesignificativa $(p>0,05)$. Outros autores estudaram o efeito dosistema PD sob os atributos físi cos do solo e evidenciaram esse aumento da Ds, devido à compactação causada pel o tráfego de máquinas eao não revolvimento do sol o (Fabrizzi et al., 2005; Cardoso et al., 2006).

Deacordo com otrabalho de Suzuki et al. (2006), o valor restritivo deDs (Dsr) ao crescimento de raízes a partir do teor médio deargila (516 $\mathrm{g} \mathrm{kg}^{-1}$, Quadro 1), em queDsr $=1,79420-0,00074$ argila, foi igual a 1,41 $\mathrm{Mg} \mathrm{m}^{-3}$. Observa-se que as parcelas experimentais

Quadro 2. Análise descritiva da densidade do solo (Ds) e parâmetros da regressão do modelo $\log K_{a}=\log M+N \log \varepsilon_{a}$, de um Latossolo Vermelho distrófico sob plantio di reto (PD), plantio direto com

\begin{tabular}{|c|c|c|c|c|c|c|c|c|c|}
\hline Tratamento & Mínimo & Média & Máximo & DP & CV (\%) & $\log (M)$ & $\mathbf{N}$ & $\mathbf{R}^{2}$ & $\varepsilon_{\mathrm{b}}(\% \mathrm{v} / \mathrm{v})$ \\
\hline & & & & & $0,0-0,1 \mathrm{~m}$ & & & & \\
\hline PD-E & 0,96 & 1,12 & 1,28 & 0,101 & 9,00 & 2,74 & 2,59 & 0,44 & 8,79 \\
\hline PD-B & 0,99 & 1,11 & 1,24 & 0,085 & 7,64 & 2,43 & 2,06 & 0,64 & 6,61 \\
\hline \multirow[t]{2}{*}{ PD } & 1,05 & 1,17 & 1,26 & 0,073 & 6,23 & 2,39 & 2,39 & 0,52 & 10,02 \\
\hline & & & & & $0,1-0,2 \mathrm{~m}$ & & & & \\
\hline PD-E & 1,14 & 1,27 & 1,34 & 0,057 & 4,49 & 1,97 & 1,66 & 0,56 & 6,46 \\
\hline PD-B & 1,21 & 1,27 & 1,36 & 0,047 & 3,68 & 1,81 & 1,48 & 0,56 & 5,99 \\
\hline \multirow[t]{2}{*}{ PD } & 1,19 & 1,27 & 1,37 & 0,065 & 5,12 & 1,78 & 1,44 & 0,42 & 5,84 \\
\hline & & & & & $0,2-0,3 \mathrm{~m}$ & & & & \\
\hline PD-E & 1,09 & 1,24 & 1,30 & 0,056 & 4,52 & 2,29 & 1,72 & 0,65 & 4,69 \\
\hline PD-B & 1,16 & 1,28 & 1,36 & 0,056 & 4,38 & 2,11 & 1,51 & 0,53 & 3,97 \\
\hline \multirow[t]{2}{*}{ PD } & 1,16 & 1,26 & 1,33 & 0,060 & 4,79 & 1,74 & 1,22 & 0,55 & 3,73 \\
\hline & & & & & $0,3-0,4 \mathrm{~m}$ & & & & \\
\hline PD-E & 1,09 & 1,22 & 1,29 & 0,061 & 4,97 & 2,28 & 1,85 & 0,63 & 5,82 \\
\hline PD-B & 1,16 & 1,24 & 1,33 & 0,053 & 4,29 & 1,90 & 1,54 & 0,64 & 5,79 \\
\hline \multirow[t]{2}{*}{ PD } & 1,08 & 1,23 & 1,28 & 0,066 & 5,40 & 2,02 & 1,52 & 0,39 & 4,73 \\
\hline & & & & & $0,4-0,5 \mathrm{~m}$ & & & & \\
\hline PD-E & 1,12 & 1,20 & 1,27 & 0,052 & 4,32 & 2,09 & 1,52 & 0,62 & 4,20 \\
\hline PD-B & 1,12 & 1,20 & 1,29 & 0,047 & 3,89 & 2,12 & 1,71 & 0,66 & 5,77 \\
\hline PD & 1,07 & 1,18 & 1,25 & 0,055 & 4,61 & 1,61 & 1,07 & 0,58 & 3,15 \\
\hline
\end{tabular}
escarificação (PD-E) e plantio di reto com descompactação biológica (PD-B), nas camadas avaliadas

$\mathrm{N}=12$ para análise descritiva; $\mathrm{N}=60$ para parâmetros da regressão; DP: desvio-padrão; CV: coeficiente de variação; log(M): intercepto com o eixo $\log \left(\mathrm{K}_{\mathrm{a}}\right) ; \mathrm{N}$ : inclinação da reta; $\mathrm{R}^{2}$ : coeficiente de determinação; $\varepsilon_{\mathrm{b}}: 10^{-\log M / N} \times 100$, prosidade bloqueada. 
avaliadas não apresentaram grau de compactação inicial elevado, indicado pelos val ores de Ds $<$ Dsr.

Não houvediferença significativa entre os valores deDs medidos numa mesma camada de solo (Figura 2). Também não foi verificada mel horia significativa na Ds na camada superficial do solo $(0,0-0,1 \mathrm{~m})$ após o uso do nabo forrageiro, devido ao grande diâmetro de sua raiz principal, como descrito por Kubota et al. (2005) para um solo de textura franco-argilosa (34\% de argila e $43 \%$ de areia). Portanto, nem a escarificação mecânica ou a descompactação biológica mostraram-sealternativas eficientes para melhorar a qualidadefísica do sol oquando o parâmetroavaliado foi a Ds. A semelhança do valor da Ds em solo escarificado (PD-E) em relação ao sol o não mobilizado possivelmente está relacionada ao processo de reconsol idação dosolo, ocorridono período de 18 meses entre a implantação do tratamento ea deter mi nação da Ds. Como a Ds no plantio direto (PD) não era el evada, a mobilização do sol o por meio da escarificação não aumentou significativamente seu espaço poroso.

O volume total de poros ficou acima de $0,50 \mathrm{~m}^{3} \mathrm{~m}^{-3}$ em todas as camadas nos três sistemas de manejo avaliados (F igura 3a), considerado ideal para um solo bem estruturadoe com condi ções satisfatórias para o crescimento de plantas (Kiehl, 1979; Brady \& Weil, 2007). A análiseda porosidadetotal do solo(PT) pode ser feita a partir da figura 3a, na qual se observa que a camada mais superficial possui quantidadedeporos significativamente maior $(p \varangle 0,05)$ em relação às demais, assim como Dalmago et al. (2009), que encontraram PT cerca de $17 \%$ mais alta em PD em comparação ao tratamento onde o sol o foi mobilizado.

Embora o volume de macroporos seja

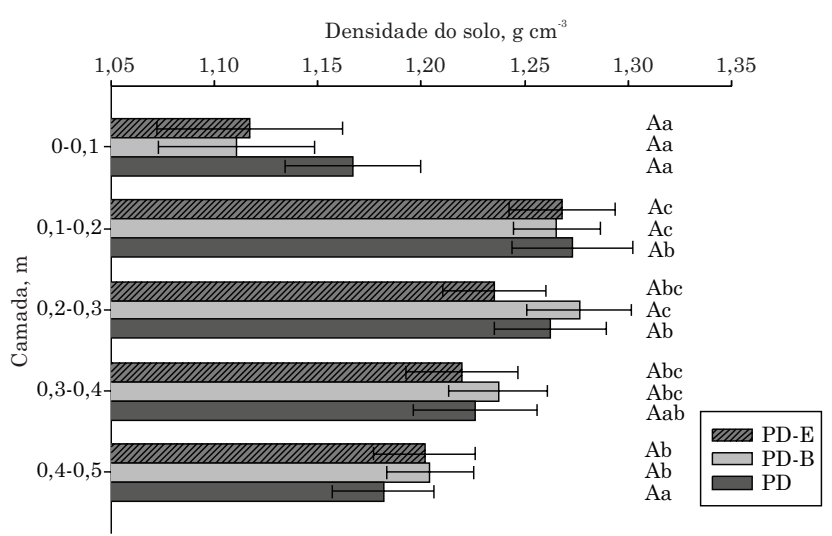

Figura 2. Valores médios de densidade do solo de um Latossolo Vermelho distrófico sob plantio direto (PD), plantio di reto com escarificação (PD-E) e plantio direto com descompactação biológica (PD-B), nas camadas de 0,0-0,1, 0,1-0,2, 0,2-0,3, 0,3-0,4 e 0,4-0,5 m. Letras maiúsculas referemse aos tratamentos e, minúsculas, às camadas; letras iguais indicam médias não diferentes devido à sobreposição dos intervalos de confiança (95\%). $\mathrm{N}=12$. numericamente maior na camada de 0,0-0,1 m, onde houve mobilização do solo através da escarificação e atuação de raízes do nabo forrageiro, essa diferença não foi significativa $(p>0,05)$ (F igura $3 b)$. Os val ores da macroporosidade nas camadas $0,1-0,2 ; 0,2-0,3 ; 0,3-$ 0,4 ; e 0,4-0,5 $\mathrm{m}$ foram inferiores a $0,10 \mathrm{~m}^{3} \mathrm{~m}^{-3}$, provavelmente em razão do intenso tráfego de máquinas associado à não mobilização do solo (Tormena et al., 1998).

Um sol o fisicamente adequado ao crescimento de plantas deve apresentar, no mínimo, $10 \%$ de macroporos, a fim de que se mantenham os níveis adequados deaeração do solo (Grable\& Siemer, 1968; Baver et al. 1972; Carter, 1988; Drewry et al., 2008). As descompactações mecânica e biológica apresentaram diferenças significativas $(p<0,05)$ de macroporosidade entre as camadas de 0,0-0,1 e 0,1$0,2 \mathrm{~m}$. Os maiores valores de macroporosidade na camada de 0,0-0,1 m demonstram a eficiência dessas práticas na mobilização do sol oeconsequenteformação de por os destinados às trocas gasosas, infiltração da água e desenvol vimento radicular. A camada de 0,1$0,2 \mathrm{~m}$ foi a que apresentou maior redução na macroporosidade, associada à mai or Ds, o que indica que a compactação do solo em semeadura direta normalmente se encontra na camada entre 0,08 e $0,15 \mathrm{~m}$ (Reichert et al., 2003; Genro J unior et al., 2004). Na camada de 0,1-0,2 m, para o PD-E, e na camada de 0,2-0,3 m, para o PD-B, os valores de macroporosidade el evaram-se gradualmente para mais próximos aos da camada superficial, o que pode ser reflexo da menor interferência da pressão exercida pel o tráfego de máquinas na estrutura do sol o com o aumento de sua profundidade.

Com oaumento da Ds os macroporos sofrem maior redução e, consequentemente, aumento dos microporos, reduzindo a PT, porém em menor proporção quea macroporosidade (Araújo, 2004). Essa rel ação pode ser verificada na figura 3 , no tratamento PD-E, o qual apresentou menor macroporosidade na camada mais compactada $(0,1-0,2 \mathrm{~m})$ e maior microporosidade entre os tratamentos. A redução do volume de macroporos do sol o pode restringir ofluxo de água e nutrientes na zona de desenvolvimento radicular.

A microporosidade (poros $<60 \mu \mathrm{m}$ ) praticamente não foi alterada de forma significativa pelos tratamentos, exceto oPD-E na camada de 0,1-0,2 m, queapresentou microporosidadesignificativamente maior $(p<0,05)$ quea dos demais tratamentos (Figura 3c), indicando que essa classe detamanho de poros foi pouco influenciada pelos manejos aplicados. Os resultados encontrados para a mi croporosidadeestão coerentes com os de Ds e PT, pois, nas camadas do sol o mais compactadas, predominou a classe de poros com diâmetro $<60 \mu \mathrm{m}$. E fatoencontrado comumente na literatura oaumento da proporção de poros demenor diâmetro em virtude da redução dos poros de maior diâmetro com o aumento da Ds (Hill et al., 1985; Streck, 2007). 


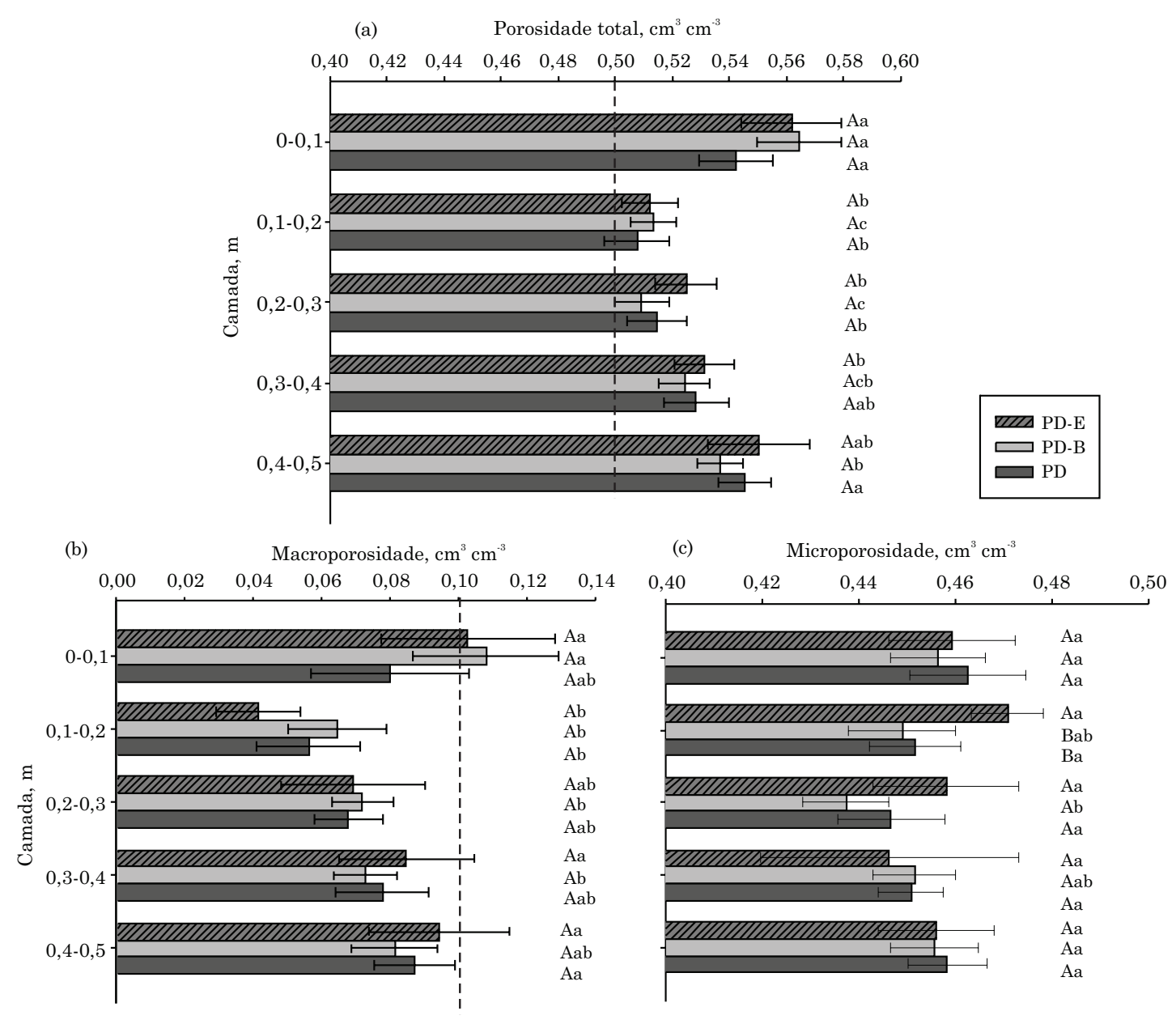

Figura 3. Valores médi os de porosidade total (a), macroporosidade (b) e microporosidade (c) de um Latossolo Vermelho distrófico sob plantio di reto (PD), plantio direto com escarificação (PD-E) e plantio di reto com descompactação biológica (PD-B), nas camadas de 0,0-0,1, 0,1-0,2, 0,2-0,3, 0,3-0,4 e 0,4-0,5 m. Nas alíneas a e b, as linhas tracejadas representam o valor de porosidade total considerado ideal (BRADY \& WE IL, 2007) e o limite crítico de macroporosidade para o desenvolvimento de plantas (BAVER et al., 1972), respectivamente. Letras maiúsculas referem-se aos tratamentose, mi núsculas, às camadas; letras iguais indicam médias não di ferentes devido à sobreposi ção dos interval os de confiança (95\%). N=12.

No presente trabalho, aos 18 meses após a descompactação também não foram detectadas diferenças entre os tratamentos, comoindicado pel os valores de PT e macroporosidade (Figura $3 a, b$ ). Camara \& Klein (2005) não detectaram efeitos da escarificação em plantio direto aos seis meses após essa operação. Vários autores justificam o fato de o efeito da mobilização do sol o desaparecer em razão da reconsol idação do solo que ocorre devido aos ciclos de umedecimento e secagem, ao impacto das gotas de chuva eao tráfego das máquinas agrícolas utilizadas na semeadura, col heita e tratos culturais (Veiga et al., 2008; Reichert et al., 2009).

A normalidade dos dados de permeabilidadeao ar $\left(K_{a}\right)$ foi verificada com o teste de normalidade de Shapiro\& Wilk (1965), e a distribuição dos dados de $\mathrm{K}_{\mathrm{a}}$ dentrodos tratamentos foi encontrada como sendo assimétrica enão normal. Assim, os logaritmos de $K_{a}$ foram utilizados para tornar as distribuições mais próximas da normalidade (Groenevelt et al., 1984; Ball et al., 1988; Blackwell et al., 1990). Apenas os potenciais mátricos a partir de $-5,0 \mathrm{kPa}$ foram utilizados na avaliação da permeabilidadeao ar e na estimativa dos índices de continuidade de poros, pois em condições de $\psi_{m}$ maiores $(-0,5 ;-1,0 ;-2,0$ e-3,0 kPa) o solo apresentou-se impermeável ou, em raras medi ções, com bai xos valores de $K_{a}$. I sso pode causar déficit de aeração mais prolongado, já que a região possui volume elevado de chuvas. Assim, pode-se inferir que a aeração do solo poderá ser mais prejudicada até o $\psi_{\mathrm{m}}$ de $-3,0 \mathrm{kPa}$, pois os poros $(<100 \mu \mathrm{m})$ encontram-se preenchidos por água. Nesse contexto, os efeitos del etérios na planta dependem do tempo necessário para o restabel eci mento da aeração no solo (Drew \& Linch, 1980), que poderia ser menor 
caso fossem detectados valores de $K_{a}>1 \mu m^{2}$ (Ball, 1981b) em $\psi_{m}$ maiores que-3,0 kPa.

Os valores médios delog $\mathrm{K}_{\mathrm{a}}$ emtodosos $\psi_{\mathrm{m}}(<-5,0 \mathrm{kPa})$ estão apresentados na figura 4. Houve efeito significativo $(p<0,05)$ para os sistemas de manejo apenas no $\psi_{\mathrm{m}}$ de $-5,0 \mathrm{kPa}$, na camada de 0,1-0,2 m, onde o tratamento com nabo forragei ro apresentou permeabilidade do solo ao ar maior que a do PD-E. Isso pode ser relacionado ao fato de oPD-B possuir, numericamente, maior macroporosidade nessa camada (Figura 3b). Coma redução do $\psi_{m}(<-5,0 \mathrm{kPa})$, não se verificam diferenças entre os tratamentos já

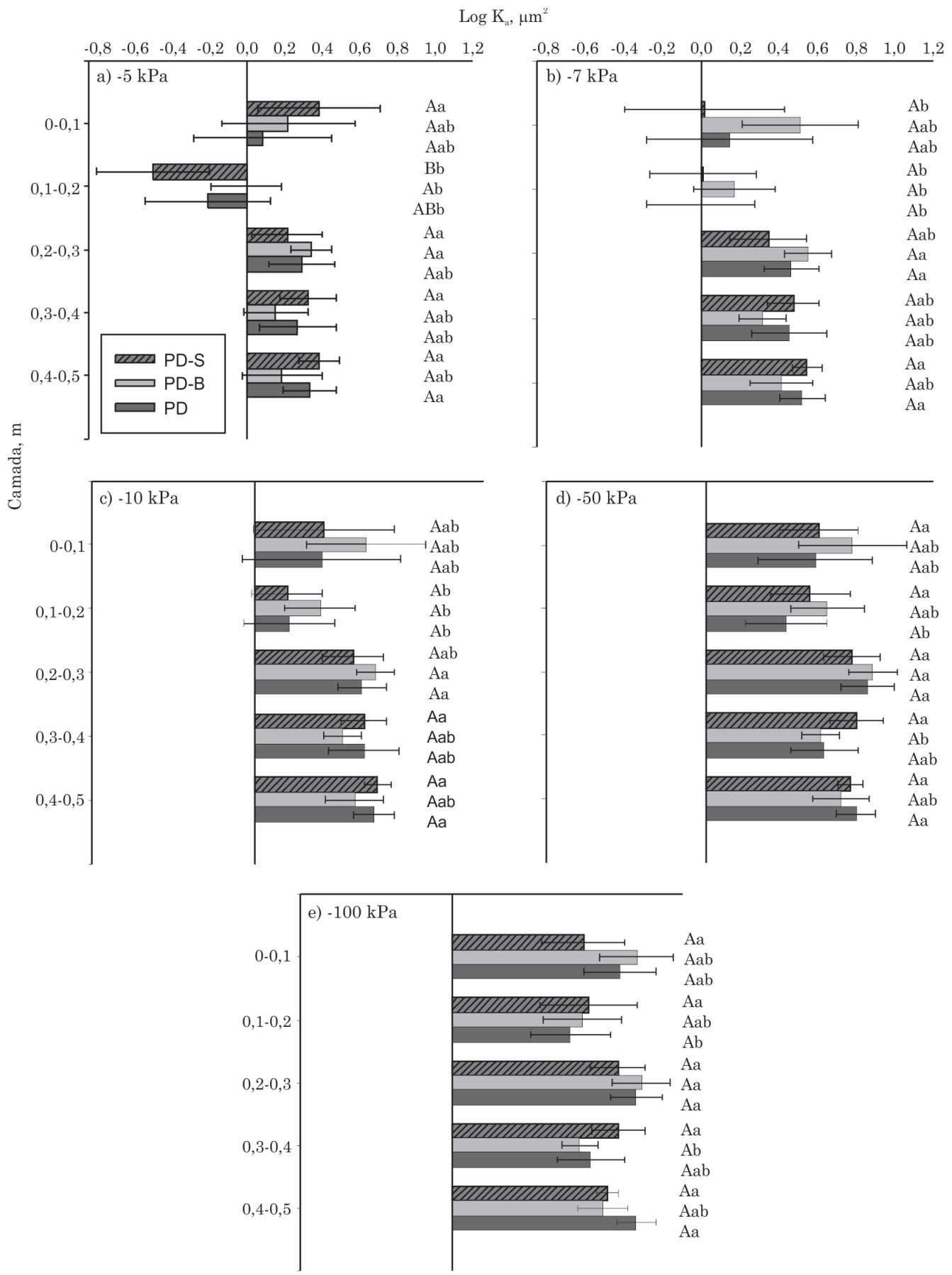

Figura 4. Valores médios do log da permeabilidade ao ar $\left(K_{\mathrm{a}}\right)$ de um Latossolo Vermelho distrófico sob plantio direto (PD), plantio direto com escarificação (PD-E) e plantio direto com descompactação biológica (PD-B), nas camadas de 0,0-0,1, 0,1-0,2, 0,2-0,3, 0,3-0,4 e 0,4-0,5 m, para diferentes potenciais matriciais: -5 kPa (a), -7 kPa (b), -10 kPa (c), $-50 \mathrm{kPa}$ (d) e-100 kPa (e). Letras maiúsculas referem-se aos tratamentos e, minúsculas, às camadas; letras iguais indicam médias não diferentes devido à sobreposi ção dos intervalos de confiança (95\%). N=12. 
que os poros menores (diâmetros equivalentes $<60 \mathrm{~mm}$ ) passam a ter maior influência na condução de ar. Portanto, a $K_{a}$ não foi significativamente alterada pela ação dos tratamentos. Por ser um parâmetro com grandevariabilidadeespacial no solo, e dependente principalmente da quantidade e continuidade dos macroporos, a $\mathrm{K}_{\mathrm{a}}$ mostrou comportamento semel hante à macroporosidade, praticamente sem diferenças significativas entre tratamentos. No entanto, esses resultados confirmam o efeito positivo do secamento do sol o no aumento da $\mathrm{K}_{\mathrm{a}}$ (Aljibury \& Evans, 1965).

$N$ ão foram verificados val ores médios de $K_{a}$ mais el evados na camada de 0-0,10 m em relação às mais profundas. Esses resultados diferem dos de Streck (2007) eSequinatto (2010), os quais verificaram, na camada de 0,0-0,1 m, maiores valores de permeabilidadeaoar. Nesses casos, nãofoi verificada al teração na estrutura do sol o pela compactação, que reduziria a permeabilidade ao ar em superfície (F ontanela, 2008; Brandt, 2009).

Em todos os tratamentos e camadas houve incremento de $\mathrm{K}_{\mathrm{a}}$ com a redução do $\psi_{\mathrm{m}}$; os por os que estavam ocupados por água gradual mente cederam espaço para o processo de aeração: primeiramenteos macroporos e, em seguida, os poros menores. A Ka apresentou, numericamente, decréscimo da camada de solo de 0,0-0,1 m para a de 0,1-0,2 m, em função da reduçãodevolume de macroporos (F igura $3 b$ ). Esse fato foi observado apenas nos val ores de $\psi_{\mathrm{m}}$, em que os macroporos estão preenchidos por água (<-10 kPa). Ou seja, o fluxo de ar preferencial ocorre pelos macroporos contínuos. Dessa forma, a permeabilidade aoar, medida próxima à capacidadedecampo, permite uma estimativa adequada da condutividade dos poros grandes (I versen et al., 2003). Resultados semel hantes também foram obtidos por Streck (2007), que determinou a condutividadeaoar em sol os submetidos a diferentes manejos e concluiu que ela se mostrou bastantedependenteda macroporosidade, expressando as alterações na estrutura do sol o quando a proporção de macroporos foi alterada.

Para determinar seas diferenças de $K_{a}$ podem ser atribuídas somenteàquel as de $\varepsilon_{a}$ ou se elas deveriam ser atribuídas a outros aspectos geométricos do espaço poroso preenchido com ar, tais como a tortuosidadee continuidade, foi utilizado oíndice de continuidade de poros $\mathrm{K}_{1}$, que corresponde ao cál culo da razão $\mathrm{K}_{a} / \varepsilon_{a}$ (Groenevelt et al., 1984). Assim comoK ${ }_{a}$, oíndice de continuidade de poros $K_{1}$ apresentou distribuiçãolognormal, de forma que todas as análises posteriores foram executadas utilizando a transformação logarítmica para cada amostra individualmente. Contudo, as anál ises de $\log \mathrm{K}_{\mathrm{a}} / \varepsilon_{\mathrm{a}}$ não foram sensíveis osuficiente para diferenciar efeitos entre porosidade, distribuição dotamanho econtinuidadedeporos entre os tratamentos propostos em nenhum potencial mátrico avaliado (Figura 5).

$A K_{a}$ foi relacionada com a $\varepsilon_{a}$ por um modelo exponencial (Equação 7), obtendo-se as constantes M
eN. A inclinação da reta (N) da relaçãolog-log entre $\mathrm{K}_{\mathrm{a}}$ e $\varepsilon_{\mathrm{a}}$ representa um índice de continuidadede poros, que determina a percentagem de poros contínuos interligados disponíveis para ofluxo dear. Esseíndice de continuidade de poros éum indicativo da eficiência dos poros em permitir a passagem do ar (Ball et al., 1988). Streck (2007) afirma que mais importanteque a porosidade é a continuidade de poros, pois poros obstruídos não contribuem para a real ização da troca gasosa entre o sol o ea atmosfera. Como indicado na figura 6, ocorreu redução noval or médio de $\mathrm{N}$ entrea camada mais superficial $(0,0-0,1 \mathrm{~m})$ e as demais camadas de solo para todos os sistemas de manejo. Esses resultados sugerem decréscimo na continuidade dos poros ou maior tortuosidade em profundidade, exceto para PD-B, o que pode ser atribuído à alta variabilidade dos valores de $\mathrm{N}$ na camada mais superficial.

Para os sistemas de manejo e as camadas de solo avaliadas, foram obtidos val ores deM eN considerando cinco $\psi_{m}$ (Figura 7). Desse modo, cerca de $56 \%$ da variabilidade de $K_{a}$ foi explicada pelo modelo da regressão (Quadro3) - resultado semel hanteao obtido por Rodrigues et al. (2011). O índice de continuidade de poros $\mathrm{N}$ apresentou diferença não significativa $(p>0,05)$ entre os três sistemas nas quatro primeiras camadas, e somente na camada de 0,4-0,5 m o tratamentoPD-E diferiu ( $F=6,5878 ; p=0,01130)$ dos demais.

Os valores médi os da porosidade bl oqueada $\left(\varepsilon_{b}\right)$ não mostraram diferença significativa $(p>0,05)$ entre os tratamentos nem entre camadas (Figura 8). Utilizando esse mesmo atributo para um solo francoargil oso, Ball et al. (1988) estimaram valores de $\varepsilon_{b}$ ligeiramente inferiores aos encontrados (Quadro 3) na faixa de 0 a 3,6 \%, com os maiores valores sob semeadura direta. I sso pode ser atribuído à diferença entre os tamanhos de partículas e, consequentemente, a um sistema poroso menos tortuoso e mais contínuo.

A porosidade de aeração na capacidade de campo de -10 kPa não apresentou diferenças estatísticas $(p>0,05)$ entre os tratamentos em nenhuma das camadas avaliadas (F igura 9). O PD-E, na camada de 0,1-0,2 m, apresentou val or de $\varepsilon_{a}$ abaixo do limite adequado para o desenvol vimento das plantas, quando a porosidade deaeração deveser denomínimo 0,10 $\mathrm{m}^{3}$ $\mathrm{m}^{-3}$ (Grable \& Siemer, 1968; Baver et al.,1972; Drewry et al., 2008). Portanto, nesse caso, pode ocorrer limitação nas trocas gasosas entre o ar da rizosfera e a atmosfera externa, o que reduz a taxa de respi ração radicular e compromete a absorção de nutrientes pelas raízes das plantas (Morard \& Silvestre, 1996). Essa limitação pode ser agravada em períodos mais chuvosos, nos quais ofluxo de ar no soloé mais prejudicado, já quea partir da camada de 0,1-0,2 $m$ todos tratamentos apresentam valores médios próximo aolimite crítico de $0,10 \mathrm{~m}^{3} \mathrm{~m}^{-3}$ ( Linn \& Doran, 1984). 
$\log \mathrm{K}_{1}, \mu \mathrm{m}^{2}$
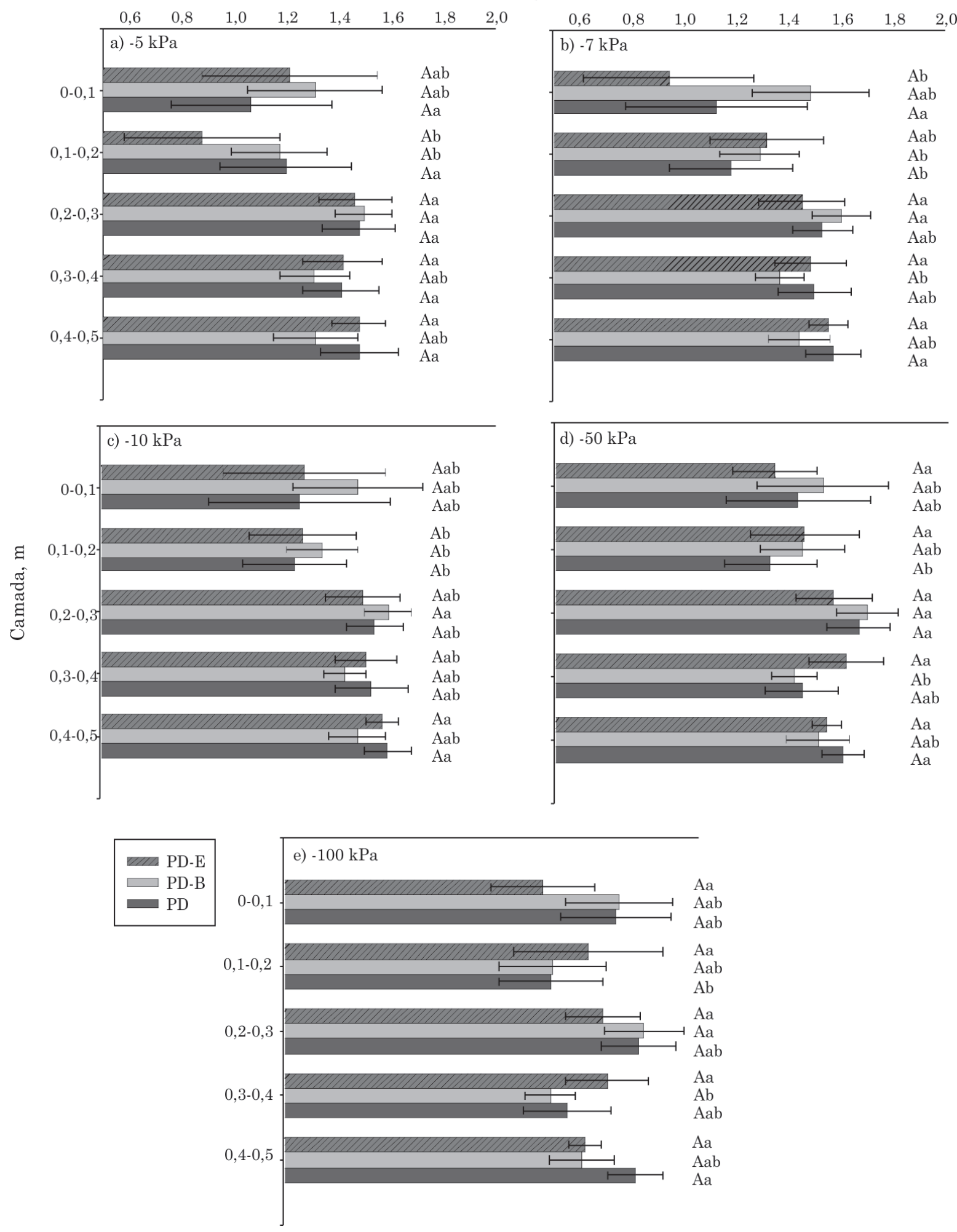

Figura 5. Valores médios do log do índice de continuidade de poros, $K_{1}$, derivado da razão entre permeabilidade ao ar e porosidade de aeração $\left(\mathrm{K}_{\mathrm{a}} / \varepsilon_{\mathrm{a}}\right)$ de um Latossolo Vermelho distrófico sob plantio direto (PD), plantio direto com escarificação (PD-E) e plantio direto com descompactação biológica (PD-B), nas camadas de 0,0-0,1, 0,1-0,2, 0,2-0,3, 0,3-0,4 e,4-0,5 m, para diferentes potenciais matriciais: $-5 \mathrm{kPa}(\mathrm{a}),-7$ $\mathrm{kPa}$ (b), -10 kPa (c), -50 kPa (d) e -100 kPa (e). Letras maiúsculas referem-se aos tratamentos e, minúsculas, às camadas; letras iguais indicam médias não diferentes devido à sobreposi ção dos intervalos de confiança (95\%). N=12. 


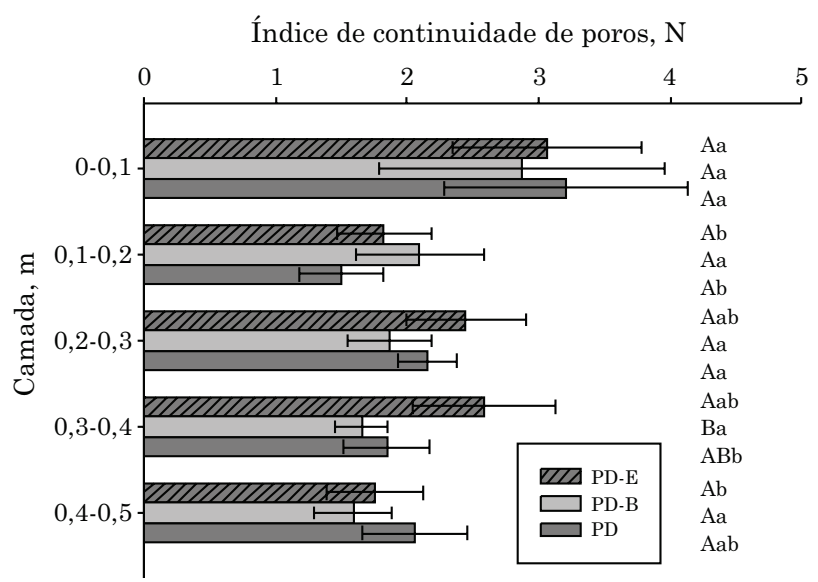

Figura 6. Valores médios do parâmetro $N$, do modelo: $\log K_{a}=\log M+N \log \varepsilon_{a}$, para um Latossolo Vermelho distrófico sob plantio direto (PD), plantio direto com escarificação (PD-E) e plantio direto com descompactação biológica (PD-B), nas camadas de 0,0-0,1, 0,1-0,2, 0,2-0,3, 0,3-0,4 e 0,4-0,5 m. Letras maiúsculas referem-se aos tratamentos e, minúsculas, às camadas; letras iguais indicam médias não diferentes devido à sobreposição dos intervalos de confiança (95\%). N=12.

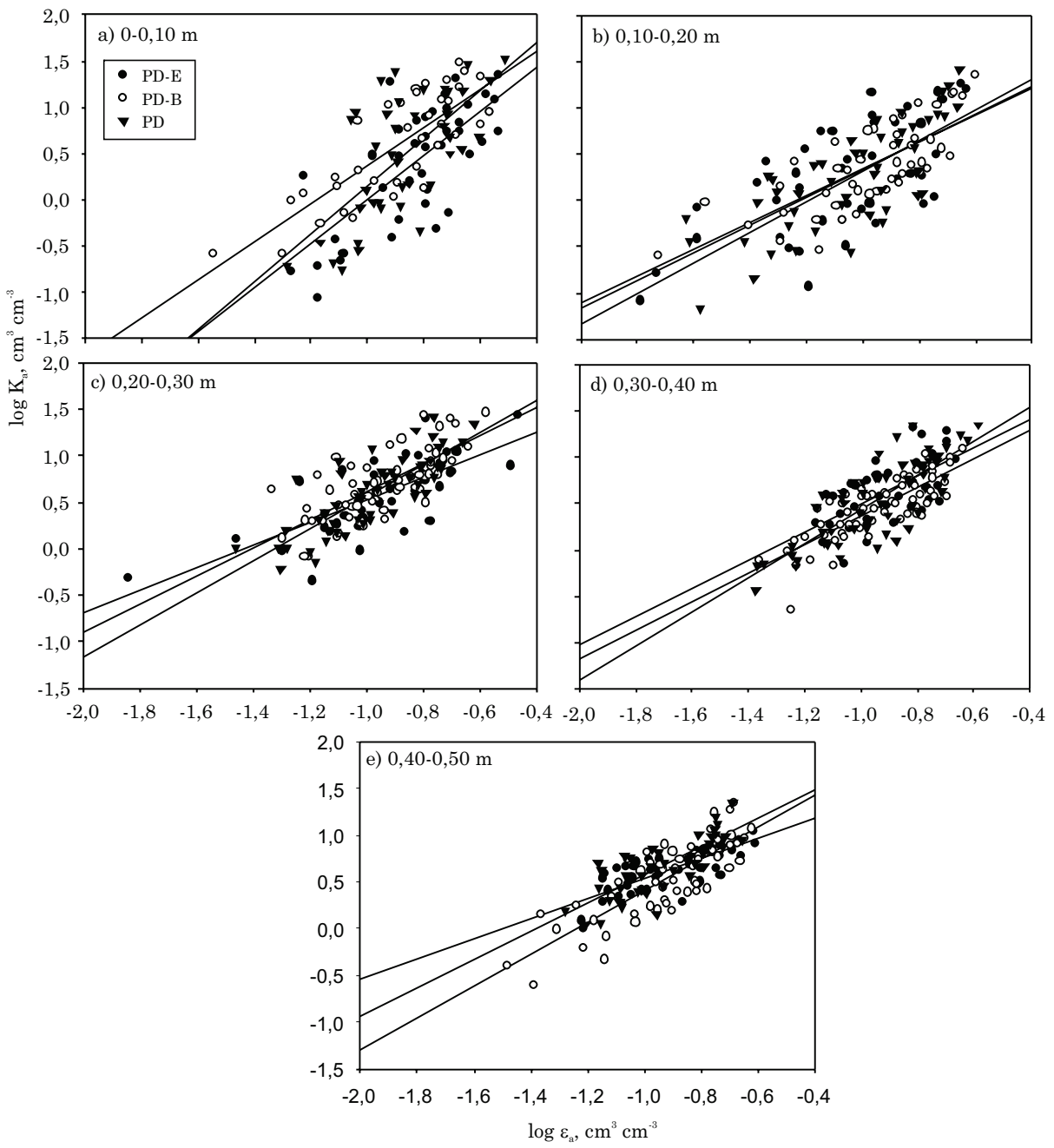

Figura 7. Relação log-log entrea permeabilidade ao ar $\left(K_{a}\right)$ e porosidade de aeração $\left(\varepsilon_{a}\right)$ de um Latossolo Vermelho distrófico sob plantio direto (PD), plantio direto com escarificação (PD-E) e plantio direto com descompactação biológica (PD-B ), nas camadas de 0,0-0,1 (a), 0,1-0,2 (b), 0,2-0,3 (c), 0,3-0,4 (d) e 0,4-0,5 (e) $\mathrm{m}$. Os pontos representam valores obtidos em cinco potenciais mátricos $(-5,-7,-10,-50$ e $-100 \mathrm{kPa}) . \mathrm{N}=60$. 


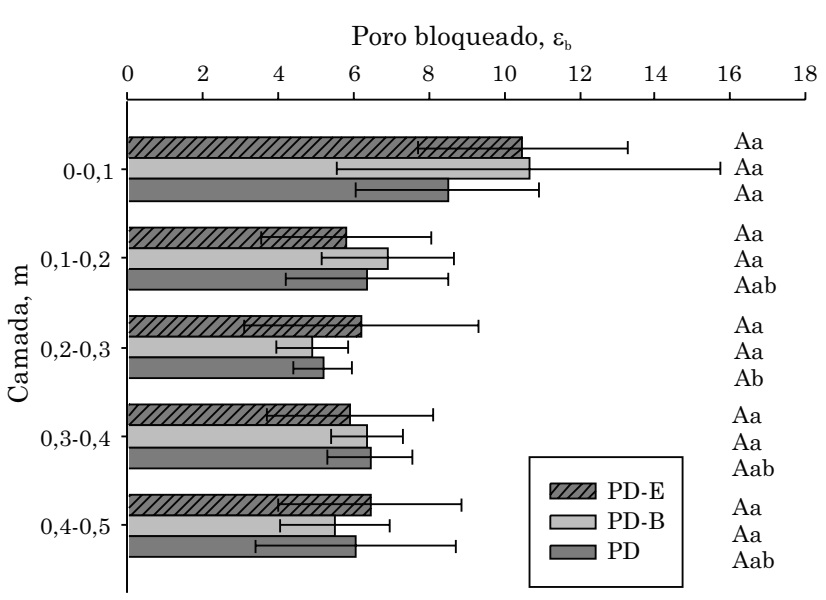

Figura 8. Valores médios da porosidade bloqueada $\left(\varepsilon_{b}=100 \times 10^{-} \log (\mathrm{M}) / \mathrm{N}, \% \mathrm{v} / \mathrm{v}\right)$ para um Latossolo Vermelho distrófico sob plantio direto (PD), plantio direto com escarificação (PD-E) e plantio direto com descompactação biológica (PD-B), nas camadas de 0,0-0,1, 0,1-0,2, 0,2-0,3, 0,3-0,4 e 0,4-0,5 m. Letras maiúsculas referem-se aos tratamentos e, minúsculas, às camadas; letras iguais indicam médias não diferentes devido à sobreposi ção dos intervalos de confiança (95\%). $\mathrm{N}=\mathbf{1 2}$.

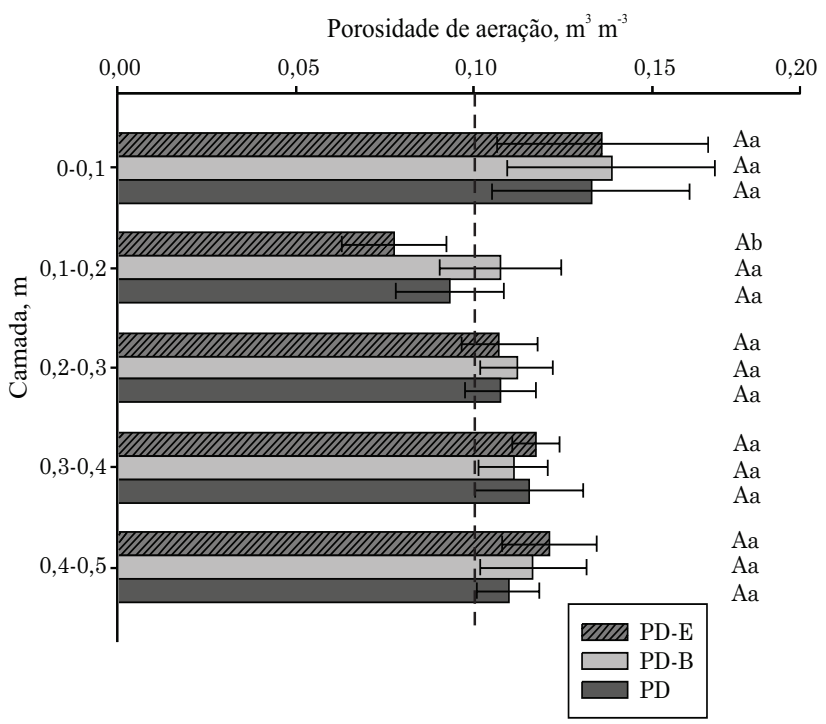

Figura 9. Valores médios da porosi dade de aeração na capacidade de campo (-10 $\mathrm{kPa}$ ) para um Latossolo Vermelho distrófico sob plantio direto (PD), plantio di reto com escarificação (PD-E) e plantio direto com descompactação biológica (PD-B), nas camadas de 0,0-0,1, 0,1-0,2, 0,2-0,3, 0,3-0,4 e 0,4-0,5 m. A linha tracejada representa o valor crítico de porosi dade de aeração de 0,10 $\mathrm{m}^{3} \mathrm{~m}^{-3}$, proposto por Baver et al. (1972). Letras maiúsculas referem-se aos tratamentos e, minúsculas, às camadas; letras iguais indicam médias não diferentes devido à sobreposição dos intervalos de confiança (95\%). $\mathbf{N}=\mathbf{1 2}$.

\section{CONCLUSÕES}

1. Após 18 meses, o plantio direto, com ou sem práticas de descompactação, apresentou praticamente a mesma qualidade física, como indicado pela densidade do solo, porosidade, permeabilidade ao ar e continuidade de poros. Portanto, constatou-se limitada persistência do efeito da escarificação como tentativa de melhorar a qualidade física de um Latossolo de textura argilosa quando o grau de compactação inicial não é restritivo ao cresci mento de plantas.

2. Entre camadas, onde a densidade do solo foi maior $(0,1-0,2 \mathrm{~m})$, a porosidade total e a permeabilidade do solo ao ar $\left(\psi_{\mathrm{m}}=-5 \mathrm{kPa}\right)$ foram menores que na camada de 0,0-0,1 m. Onde houve escarificação, a macroporosi dadefoi mai or na camada mais superficial.

3. Os índices de continuidade de poros $\left(\mathrm{K}_{1} \mathrm{eN}\right)$ não foram sensíveis em detectar diferenças na qualidade física do solo.

\section{LITE RATURA CITADA}

ABREU, S.L.; REICHERT, J .M. \& REINERT, D.J . Escarificação mecânica e biológica para a redução da compactação em Argissolo franco-arenoso sob plantio direto. R. Bras. Ci. Solo, 28:519-531, 2004.

ALJ IBURY, F.K. \& EVANS, D.D. Water permeability of saturated soils as related to air permeability at different moisture tensions. Soil Sci. Soc. Am. Proc., 29:366-369, 1965.

ARAÚJ O, A.G. Estimativa e classificação da compactação do solo pelo tráfego de máquinas agrícolas através da modelagem nebulosa. São Paulo, Escola Politécnica, Universidade de São Paulo, 2004. 224p. (Tese de Doutorado)

BALL, B.C. Modeling of soil pores as tubes using gas permeabilities, gas diffusivities and water release. J. Soil Sci., 32:465-481, 1981a.

BALL, B.C. Pore characteristics of soils from two cultivation experiments as shown by gas diffusivities and permeabilities and air-filled porosities. J . Soil Sci., 32:483498, 1981b.

BALL, B.C.; O'SULLIVAN, M.F. \& HUNTER, R. Gas diffusion, fluid flow and derived pore continuity indices in relation to vehicle traffic and tillage. J. Soil Sci., 39:327-339, 1988.

BAVER, L.D.; GARDNER, W.H. \& GARDNER, W.R. Soil physics. 4.ed. New York, J ohn Wiley, 1972. 498p.

BEUTLER, A.N.; SILVA, M.L.N.; CURI, N.; FERREIRA, M.M.; CRUZ, J.C. \& PEREIRA FILHO, I.A. Resistência à penetração e permeabilidade de Latossolo Vermelho distrófico típico sob sistemas de manejo na região dos cerrados. R. Bras. Ci. Solo, 25:167-177, 2001. 
BHERING, S.B.; SANTOS, H.G.; BOGNOLA, I.A.; CÚRCIO, G.R.; MANZATTO, C.V.; CARVALHO JUNIOR, W.; CHAGAS, C.S. \& ÁGLIO, M.L.D. \& SOUZA, J.S. Mapa de solos do Estado do Paraná: Legenda atualizada. Rio de J aneiro, Embrapa/IAPAR, 2008. 74p.

BLACKWELL, P.S.; RINGROSE-VOASE, A.J .; J AYAWARDANE, N.S.; OLSSON, K.A.; MCKENZIE, D.C. \& MASON, W.K. The use of air-filled porosity and intrinsic permeability to air to characterize structure of macropore space and saturated hydraulic conductivity of clay soils. J . Soil Sci., 41:215-228, 1990.

BLAKE, G.R. \& HARTGE, K.H. Bulk density. In: KLUTE, A., ed. Methods of soil analysis. American Society of Agronomy/Soil Science Society of America, 1986. p.363375.

BRADY, N. \& WEIL, R.R. The nature and properties of soils. 14.ed. New J ersey, Prentice Hall, 2007. 980p.

BRANDT, A.A. Carregamento estático e dinâmico e sua relação com tensão, deformação e fluxos no solo. Santa Maria, Universidade Federal de Santa Maria, 2009. 162p. (Tese de Doutorado)

CAMARA, R.K. \& KLEIN, V.A. Escarificação em plantio direto como técnica de conservação do solo e da água. R. Bras. Ci. Solo, 29:789-796, 2005.

CARDOSO, E.G.; ZOTARELLI, L.; PICCININ, J .L.; TORRES, E.; SARAIVA, O.F. \& GUIMARÃES, M.F. Sistema radicular da soja em função da compactação do solo no sistema de plantio direto. Pesq. Agropec. Bras., 41:493501, 2006.

CARTER, M.R. Temporal variability of soil macroporosity in a fine sandy loam under moulboard ploughing and direct drilling. Soil Tillage Res., 12:35-51, 1988.

CARTER, M.R.; WHITE, R.P. \& IVANY, J.A. Characterizing macropore continuity and aeration in fine loams in tillage studies. In: INTERNATIONAL SOIL TILLAGE RESEARCH ORGANIZATION; INTERNATIONAL CONFERENCE, 13., Aalborg, 1994. Proceedings... Aalborg, Royal Veterinary and Agricultural University/ Danish Institute of Plant and Soil Science, 1994. p.7-12.

CAVALIERI, K.M.V.; DA SILVA, A.P.;TORMENA, C.A.; LEÃO, T.P.; DEXTER, A.R. \& HÅKANSSON, I. Long-term effects of no-tillage on dynamic soil physical properties in a Rhodic Ferrasol in Parana, Brazil. Soil Tillage Res., 103:158-164, 2009.

CHAMEN, T.; ALAKUKKU, L.; PIRES, S.; SOMMER, C.; SPOOR, G.; TIJ INK, F. \& WEISSKOPF, P. Prevention strategies for field traffic-induced subsoil compaction: A review. Equipment and field practices. Soil Tillage Res., 73:161-174, 2003.

COLLARES, G.L.; REINERT, D.J .; REICHERT, J.M. \& KAISER, D.R. Qualidade física do solo na produtividade da cultura do feijoei ro num Argissol o. Pesq. Agropec. Bras., 41:1663-1674, 2006.

CUBILLA, M.; REINERT, D.J .; AITA, C. \& REICHERT, J.M. Plantas de cobertura do solo: uma alternativa para aliviar a compactação em sistema plantio direto. R. Plantio Direto, 71:29-32, 2002.
DALMAGO, G.A.; BERGAMASCHI, H.; BERGONCI, J .I .; KRÜGER, C.A.M.B.; COMIRAN, F. \& HECKLER, B.M.M. Retenção e disponibilidade de água às plantas, em solo sob plantio direto e preparo convencional. R. Bras. Eng. Agríc. Amb., 13:855-864, 2009.

DREW, M.C. \& LYNCH, J .M. Soil anaerobiosis, microorganisms and root function. Ann. Rev. Phytopathol., 18:37-66, 1980.

DREWRY, J J .; CAMERON, K.C. \& BUCHAN, G.D. Pasture yield and soil physical property responses to soil compaction from treading and grazing - a review. Austr. J. Soil Res., 46:237-256, 2008.

FABRIZZI, K.P.; GARCIA, F.O.; COSTA, J.L. \& PICONE, L.I. Soil water dynamics, physical properties and corn and wheat responses to minimum and no-tillage systems in the southern Pampas of Argentina. Soil Tillage Res., 81:57-69, 2005.

FIGUEIREDO, G.C. Avanços metodológicos e instrumentais em física do solo. Piracicaba, Escola Superior de Agricultura "Luiz de Queiroz", 2010. 163p. (Tese de Doutorado)

FIGUEIREDO, G.C.; SILVA, A.P.; TORMENA, C.A.; GIAROLA, N.F.B.; MORAES, S.O. \& ALMEIDA, B.G. Desenvolvimento de consolidrômetro pneumático: Modelagem da compactação, penetrometria e resistência tênsil de agregados de solo. R. Bras. Ci. Solo, 35:389-402, 2011.

FONTANELA, E. Parâmetros físico-hídricos de um Latossolo sob diferentes sistemas de manejo e níveis de tráfego. Santa Maria, Universidade Federal de Santa Maria, 2008. 72p. (Tese de Mestrado)

FRANCHINI,J.C. \& DEBIASI, H. Manejo da compactação do solo no sistema plantio direto na palha. In: SIMPÓSIO SOBRE PLANTIO DIRETO NA PALHA, 2009, Foz do I guaçu. Palestras... Ponta Grossa, FEBRAPDP, 2009. p.27-38.

GEE, G.W. \& BAUDER, J .W. Particle-size analysis. In: KLUTE, A., ed. Methods of soil analysis: Part 1 - Physical and mineralogical methods. 2. ed. Madison, American Society of Agronomy, 1986. p.383-411.

GENRO J UNIOR, S.A.; REINERT, D.J . \& REICHERT, J .M. Variabilidade temporal da resistência à penetração de um Latossolo Argiloso sob semeadura direta com rotação de culturas. R. Bras. Ci. Solo, 28:477-484, 2004.

GERIK, T.J .; MORRISON J r., J .E. \& CICHESTER, F.W. Effect of controlled traffic on soil physical properties and crop rooting. Agron. J ., 79:434-438, 1987.

GRABLE, A.R. \& SIEMER, E.G. Effects of bulk density aggregate size and soil water suction on oxygen diffusion, redox potential and elongation of corn roots. Soil Sci. Soc. Am. J ., 32:18-186, 1968.

GROENEVELT, P.H.; KAY, B.D. \& GRANT, C.D. Physical assessment of a soil with respect to rooting potential. Geoderma, 34:101-114, 1984.

HILL, R.L.; HORTON, R. \& CRUSE, R.M. Tillage effects on soil water retention and pore size distribution of two Mollisols. Soil Sci. Soc. Am. J ., 49:1264-1270, 1985. 
HILLEL, D. F undamentals of soil physics. New York, Academic Press, 1980. 413p.

INSTITUTO AGRONÔMICO DO PARANÁ - IAPAR. Cartas climáticas do Estado do Paraná. Londrina, 2000. CD-ROM.

IVERSEN, B.V.; MOLDRUP, P.; SCHJ ONNING, P.\& J ACOBSEN, O.H. Field application of a portable air permeameter to characterize spatial variability in air and water permeability. Vadose Zone J ., 2:618-626, 2003.

KIEHL, E.J . Manual de edafologia. São Paulo, Agronômica Ceres, 1979. 262p.

KUBOTA, A.; HOSHIBA, K. \& BORDON, J. Green-manure turnip for soybean based no-tillage farming systems in eastern Paraguay. Sci. Agric., 62:150-158, 2005.

LANDEFELD, L.S.; BRANDHUBER, R.; FENNER, S.; KOCH, H.J. \& STOCKFISCH, N. Effects of agricultural machinery with high axle load on soil properties of normally managed fields. Soil Tillage Res., 75:75-86, 2004.

LETEY, J .; STOLZY, L.H.; VOLORAS, N. \& SZUSZKIEWICZ, T.E. Influence of soil oxygen on mineral concentration of barley. Agron. J ., 54:538-540, 1962.

LINN, D.M. \& DORAN, J.W. Effect of water-filled pore space on carbon dioxide and nitrous oxide production in tilled and nontilled soils. Soil Sci. Soc. Am. J ., 48:1267-1272, 1984.

MAGALHÃES, E.N.; OLIVEIRA, G.C.; SEVERIANO, E.C.; COSTA, K.A.P. \& CASTRO, M.B. Recuperação estrutural e produção do capim-Tifton 85 em um Argissolo Vermel hoAmarelo compactado. Ci. An. Bras., 10:68-76, 2009.

MORARD, P. \& SILVESTRE, J. Plant injury due to oxygen deficiency in the root environment of soilless culture: $A$ review. Plant Soil, 184: 243-254, 1996.

PAYTON, M.E.; MILLER, A.E. \& RAUN, W.R. Testing statistical hypotheses using standard error bars and confidence intervals. Commun. Soil Sci. Plant Anal., 31:547-551, 2000.

REICHERT, J .M.; REINERT, D.J . \& BRAIDA, J .A. Qualidade dos solos e sustentabilidade de sistemas agrícolas. R. Ci. Amb., 27:29-48, 2003.

REICHERT, J .M.; SUZUKI, L.E.A.S.; REINERT, D.J .; HORN, R. \& HÅKANSSON, I. Reference bulk density and critical degree-of-compactness for no-till crop production in subtropical highly weathered soils. Soil Tillage Res., 102:242-254, 2009.

RODRIGUES, S.; DA SILVA, A.P.; GIAROLA, N.F.B. \& ROSA, J.A. Permeabilidade ao ar em Latossolo Vermel ho sob diferentes sistemas de manejo. R. Bras. Ci. Solo, 35:105114, 2011.

ROSEBERG, R.J . \& McCOY, E.L. Measurement of soil macropore air permeability. Soil Sci. Soc. Am. J ., 54:969-974, 1990.
SCANLON, B.R.; NICOT, J .P. \& MASSMANN, J.W. Soil gas movement in unsaturated systems. In: WARRICK, A.W., ed. Soil physics companion. Boca Raton, CRC Press, 2002. p.297-341.

SCHJ ØNNING, P.; MUNKHOLM, L.J .; MOLDRUP, P. \& J ACOBSEN, O.H. Modelling soil pore characteristics from measurements of air exchange: The long term effects of fertilization and crop rotation. Eur. J. Soil Sci., 53:331339, 2002.

SEQUINATTO, L. Qualidade física do solo e rendimento de grãos num Argissolo em processo de recuperação. Porto Alegre, Universidade Federal do Rio Grande do Sul, 2010. 158p. (Tese de Doutorado)

SHAPIRO, S.S. \& WILK, M.B. Analysis of variance test for normality (complete samples). Biometrika, 52:591-611, 1965.

SHTYKOV, V.I. \& DAISHEV, S.T. Determination of air permeability of soils. Sov. Soil Sci., 18:115-122, 1986.

SILVA, A.P.; LEAO, T.P.; TORMENA, C.A. \& GONÇALVES, A.C.A. Determination of air permeability in undisturbed soil samples by the decreasing pressure method. R. Bras. Ci. Solo. 33:1535-1545, 2009.

SPRINGER, D.S.; LOAICIGA, H.A.; CULLEN, S.J . \& EVERETT, L.G. Air permeability of porous materials under controlled laboratory conditions. Ground Water, 36:558-565, 1998.

STONE, L.F.; GUIMARÃES, C.M. \& MOREIRA, J.A.A. Compactação do solo na cultura do feijoeiro: I. Nas propriedades físico-hídricas do solo. R. Bras. Eng. Agríc. Amb., 6:213-218, 2002.

STRECK, C.A. Índice S e fluxo de água e ar em solos do Sul do Brasil. Santa Maria, UniversidadeF ederal deSanta Maria, 2007. 95p. (Tese de Doutorado)

SUZUKI, L.E.A.S.; REINERT, D.J .; REICHERT, J .M. \& LIMA, C.L.R. Densidade restritiva ao sistema radicular em função da argila. In: REUNIÃO BRASILEIRA DE MANEJ O E CONSERVAÇÃO DO SOLO E DA ÁGUA, 16., Aracajú, 2006. Anais... Aracajú, 2006. CD-ROM.

TAYLOR, J.C. \& BELTRAME, L.F.S. Por que, quando e como utilizar a subsolagem. Lav. Arroz., 3:34-44, 1980.

TORMENA, C.A.; ROLOFF, G. \& SÁ, J.C.M. Propriedades físicas do solo sob plantio direto influenciadas por calagem, preparo inicial e tráfego. R. Bras. Ci. Solo, 22:301-309, 1998.

VEIGA, M.; REINERT, D.J .; REICHERT, J .M. \& KAISER, D.R. Short and long-term effects of tillage systems and nutrient sources on soil physical properties of a southern brazilian Hapludox. R. Bras. Ci. Solo, 32:1437-1446, 2008. 